\title{
IMPLEMENTAÇÃO DE LEAN SIX SIGMA PARA MELHORIA DE PROCES- SOS: UM ESTUDO DE CASO EM UMA EMPRESA DE TELECOMUNICAÇÕES
}

\author{
Carlos Navarro Fontanillas \\ Universidade Federal do Rio de Janeiro/UFRJ \\ Av. Pasteur, 250/238 \\ navarro@facc.ufrj.br \\ Eduardo Picanço Cruz \\ Universidade Federal Fluminense/UFF \\ Av. Santos Mario Braga, 01/722 \\ epicanco@vm.uff.br
}

\section{RESUMO}

A pesquisa que levou ao presente artigo teve como objetivo entender o processo de implementação da metodologia lean six sigma e avaliar se ela fornece processos aprimorados em uma organização, causando ganhos financeiros e reduzindo o desperdício, por exemplo. O método utilizado após o estudo bibliográfico foi um estudo de caso em uma empresa de telecomunicações que, segundo os gerentes, teve problemas no processo de desabilitação dos serviços por meio do serviço prestado via call center. A lógica teórica descreve os conceitos-chave para a compreensão da metodologia e o estudo de caso ajuda a validar, através da análise de dados e processos, os ganhos obtidos pela organização que implementou. Esses ganhos foram expostos, como melhoria de processo avaliada, redução de falhas, para evitar um custo desnecessário que permite o investimento em atividades mais produtivas.

Palavra-chave: Qualidade, processos, Lean six sigma

\begin{abstract}
The research that led to the present paper aimed to understand the process of implementing lean six sigma methodology and assess whether it provides improved processes in an organization, causing financial gains and reducing waste, for example. The method used after the bibliographic study was a case study in a telecommunication company, which according to the managers, had problems in the process of disabling services through its service provided via call center. The theoretical rationale describes key concepts for understanding the methodology and the case study helps to validate, through the analysis of data and processes, the gains made by the organization that implemented. These gains were exposed, such as process improvement assessed, reducing failures, to avoid an unnecessary cost allowing investment in more productive activities.
\end{abstract}

Keywords: Keywords: Quality, Processes, Lean six sigma. 


\section{Como Citar:}

FONTANILLAS, Carlos Navarro; CRUZ, Eduardo Picanço. Implementação de Lean Six Sigma para melhoria de processos: um estudo de caso em uma empresa de telecomunicações. In: SIMPÓSIO DE PESQUISA OPERACIONAL E LOGÍSTICA DA MARINHA, 19., 2019, Rio de Janeiro, RJ. Anais [...]. Rio de Janeiro: Centro de Análises de Sistemas Navais, 2019.

\section{INTRODUÇÃO}

A globalização intensificou a concorrência e o grau de exigência por parte do consumidor, devido a isso, as organizações passaram a buscar continuamente formas de aperfeiçoar seus processos produtivos proporcionando maior qualidade com custos reduzidos com o objetivo de fazer frente às novas características do mercado. Dentre as inúmeras metodologias associadas à qualidade, destacou-se neste paper a lean seis sigma que trata a qualidade de forma sistêmica abrangendo todas as ações e setores de uma organização e não somente as não conformidades de processos específicos. Ela tem como objetivo implantar práticas para melhorar sistematicamente os processos ao eliminar defeitos, tornando-os mais enxutos. A implementação de projetos com a utilização de tal metodologia prevê uma divisão em cinco fases: definição, medição, análise, implementação e controle. De acordo com Bernardes e Miyake [1], um dos problemas encontrados na implementação dos sistemas é a falta de padronização para o controle de qualidade dos projetos, que pode ser exemplificada pela existência de cadastros errados de códigos de identificação causando erros no fluxo de arquivos.

Foi abordado neste trabalho, um estudo de caso que descreveu o processo de implementação de um projeto lean seis sigma em uma empresa de grande porte do ramo de telecomunicações com sede na cidade do Rio de Janeiro e filiais em seis centros de atendimento (CAS) distribuídos pelo Brasil. O problema em questão estava relacionado ao seu processo de desativação dos produtos da linha para pequenas e médias empresas (PME), que não concluía a solicitação gerando duas saídas não desejadas: a primeira com a emissão de uma nova fatura após o pedido de desativação por parte do cliente e a segunda com pagamento de impostos e emissão das faturas pela organização. Neste caso observou-se prejuízo qualitativo, pelo desgaste do cliente, imagem do produto e da empresa; financeiros, pois embora a fatura fosse cancelada posteriormente, o volume mensal apresentado era alto e os custos não eram restituídos.

O projeto buscou por meio da metodologia apresentada, atuando com as ferramentas disponíveis em cada uma de suas etapas a melhoria do processo com o objetivo de corrigi-lo, gerando retorno positivo para organização.

Partindo dos pressupostos apontados em relação ao estudo de caso e com base nos conceitos e ferramentas metodológicas, este trabalho buscou responder o seguinte questionamento: Quais resultados pode-se esperar da implementação da metodologia lean seis sigma em uma organização? O trabalho partiu da suposição de que a implementação do método proporcionaria melhorias aos processos de uma organização, gerando redução de desperdícios e ganhos financeiros, seja com o aumento da receita ou redução de custo.

O objetivo final desta pesquisa é entender a relação entre a implementação da metodologia lean seis sigma com possíveis benefícios gerados e comprovar o resultado gerado pelo 
projeto considerando um estudo de caso realizado na empresa que atua no ramo de telecomunicações e que possui como base de gestão a NBR ISO 9001.

\section{MÉTODO}

Para a classificação da pesquisa realizada usa-se a metodologia apresentada por Vergara [2], que a qualifica sob dois aspectos: quanto aos fins e quanto aos meios. Quanto aos fins, a pesquisa foi descritiva e explicativa. Descritiva, porque visa expor características da implementação da metodologia lean seis sigma numa empresa do ramo de telecomunicações. Explicativa, pois reforçada ao referencial teórico, ajuda a entender como a implementação do referido método gera benefícios às organizações que a aderem, por meio da melhoria de seus processos, proporcionando, retorno financeiro e eliminando desperdícios. Quanto aos meios, a pesquisa foi bibliográfica e abrange um estudo de caso.

\section{FUNDAMENTAÇÃO TEÓRICA}

O conceito de qualidade é subjetivo e está relacionado à percepção de cada indivíduo. São inúmeras as variáveis que influenciarão na definição de um conceito mais adequado como; cultura, tipo de produto ou serviço prestado, necessidades e expectativas envolvidas, entre outras. Fundamenta Juran [3], que a qualidade é definida pela "adequação à finalidade ou uso", ou seja, uma resposta às necessidades dos clientes.

De acordo com NBR ISO 9000, o conceito de qualidade é definido como: "grau no qual um conjunto de características inerentes satisfaz a requisitos" [4], ou seja, qualidade é a adequação ao uso, a conformidade de um produto ou serviço às exigências do consumidor.

A qualidade deve ter como objetivo as necessidades do usuário, presentes e futuras, ou seja, tem a sua definição baseada na pessoa que avalia. Porém, a dificuldade de definição está na conversão de necessidades futuras do usuário de forma mensurável, na finalidade de adequar o produto a proporcionar a satisfação do cliente por um preço que esteja disposto a pagar [5].

Para as organizações é fundamental que o conceito de qualidade esteja presente em seu dia a dia na interação entre as áreas, a fim de promover maior integração e satisfação na realização de suas atividades, evitando retrabalhos e desperdícios. De acordo com Back, Kovaleski e Andrade Junior [6] um dos principais problemas diz respeito ao excesso de informações, que compreendem informações inúteis sem valor agregado e estratégico para a organização na tomada de decisão.

O mercado tem apresentado uma nova dinâmica devido a uma acirrada concorrência, exigindo das organizações mais agilidade e qualidade em suas ações. Entrementes, Fontanillas, Cruz e Gonçalves [7] ressaltam que o diferencial para empresas contemporâneas, deve ser o investimento nos ativos intangíveis (bens e direitos não palpáveis) em detrimento dos tangíveis (palpáveis físicos); o recurso mais importante não é mais de caráter financeiro e sim intelectual, baseado no conhecimento, já que uma boa gerência dos recursos financeiros depende do conhecimento humano. Torna-se necessária uma visão sistêmica, o entendimento da empresa como um conjunto de processos inter-relacionados e interdependentes, levando a administração a desvincular o foco que detinha no trabalho, departamento ou funções para o foco no gerenciamento dos processos. Estes, são compreendidos por uma ação transformadora que pode agregar valor a determinados insumos (entradas), proporcionando saídas caracte- 
rizadas como produtos ou serviços mostrados na figura 1, a seguir:

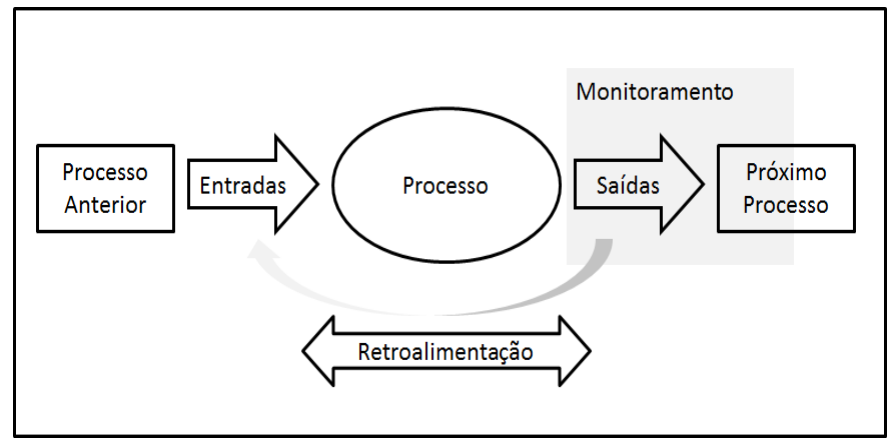

Figura 1: Esquema de um processo conforme a NBR ISO 9000 [4]

De acordo com Maranhão e Macieira [8] para efeito de organizações, o termo "processo" possui várias definições, todas análogas e complementares entre si e alinhadas conforme tabela 1 apresentada a seguir:

\section{TABELA I}

Definições de processos

\begin{tabular}{|c|c|}
\hline áfica & De \\
\hline $\begin{array}{l}\text { a NBR ISO } \\
00\end{array}$ & $\begin{array}{l}\text { Conjunto de atividades } \\
\text { inter-relacionadas } \\
\text { interativas que transforma } \\
\text { insumos (entradas) em } \\
\text { produtos (saídas). }\end{array}$ \\
\hline \begin{tabular}{lr}
\multicolumn{1}{c}{ Integration } & \\
Definition & for \\
Modeling & of \\
Process - IDEF0 &
\end{tabular} & $\begin{array}{l}\text { Conjunto de atividades, } \\
\text { funções ou } \\
\text { identificadas, que ocorrem } \\
\text { em um período de tempo e } \\
\text { que produzem algum } \\
\text { resultado. }\end{array}$ \\
\hline $\begin{array}{l}\text { Michel Hammer } \\
\text { (em Reengenharia - } \\
\text { Revolucionando a } \\
\text { empresa e a } \\
\text { Agenda) }\end{array}$ & $\begin{array}{l}\text { 1. Reunião de tarefas ou } \\
\text { atividades isoladas; } \\
2 . \quad \text { Grupo organizado de } \\
\text { atividades relacionadas que, } \\
\text { juntas, criam um resultado } \\
\text { de valor para o cliente. }\end{array}$ \\
\hline \begin{tabular}{lr}
\multicolumn{1}{c}{ Thomas } & H. \\
Davenport & (em \\
Reengenharia & de \\
Processos) &
\end{tabular} & $\begin{array}{l}\text { 1. Um conjunto de } \\
\text { atividades estruturadas e } \\
\text { medidas destinadas a resultar } \\
\text { em um produto especificado } \\
\text { para um determinado cliente } \\
\text { mercado; } \\
\text { 2. Ordenação específica } \\
\text { das atividades de trabalho, }\end{array}$ \\
\hline
\end{tabular}




\begin{tabular}{|c|c|}
\hline & $\begin{array}{l}\text { no tempo e no espaço, com } \\
\text { um começo, um fim, e } \\
\text { inputs e outputs claramente } \\
\text { identificados. }\end{array}$ \\
\hline $\begin{array}{l}\text { RohitRamaswam } \\
\text { my (emDesign and } \\
\text { Management of } \\
\text { Service Processes) }\end{array}$ & \begin{tabular}{lcr}
\multicolumn{1}{c}{ São } & sequências & de \\
atividades & que & são \\
necessárias & para realizar as \\
transações & e prestar & o \\
serviço. & & \\
\end{tabular} \\
\hline $\begin{array}{l}\text { DianneGalloway } \\
\text { (emMapping Work } \\
\text { Processes) }\end{array}$ & $\begin{array}{l}\text { Uma sequência de passos, } \\
\text { tarefas ou atividades que } \\
\text { convertem entradas de } \\
\text { fornecedores em uma saída. } \\
\text { Um processo de trabalho } \\
\text { adiciona valor às entradas, } \\
\text { transformando-as ou usando- } \\
\text { as para produzir alguma } \\
\text { coisa nova. }\end{array}$ \\
\hline \begin{tabular}{lr}
\multicolumn{1}{c}{ Geary } & A. \\
Rummier e Alan P. \\
Brache \\
Melhores \\
$\begin{array}{l}\text { Desempenhos } \\
\text { Empresas) }\end{array}$ \\
\end{tabular} & $\begin{array}{l}\text { Uma série de etapas } \\
\text { criadas para produzir um } \\
\text { serviço ou produto. }\end{array}$ \\
\hline
\end{tabular}

Fonte: Maranhão e Macieira [8]

Todo processo necessita de controle, justamente para que seus resultados sejam acompanhados. Maranhão e Macieira [8] descrevem que um processo bem controlado apresenta entradas/inputs planejados; transformações controladas; e saídas esperadas.

Não obstante, revela-se a necessidade de agregação de valor. Porter [9] descreve como o valor que os compradores estão dispostos a pagar pelo que é oferecido por uma empresa. Tal valor é atribuído pelo cliente, de acordo com seu interesse. É relevante que todo processo seja devidamente mapeado e que os próprios colaboradores contribuam com a experiência adquirida.

O lean manufacturing, ou manufatura enxuta, é uma filosofia de gestão focada na redução de desperdícios. De acordo com Vieira e Ventura [10], o lean se desenvolveu no Japão após a Segunda Guerra Mundial, num cenário de grandes dificuldades, com restrições de matérias-primas e espaço. Esta situação obrigou as empresas a se tornarem altamente eficientes através da mentalidade enxuta, que consiste em produzir só o que foi efetivamente vendido, buscar incansavelmente a melhoria de qualidade e diminuir ao máximo a utilização de recursos. Segundo Moreira [11], na manufatura a qualidade é um componente importante em todos os seus processos. Apresenta a necessidade de atuar em atividades que não agregam valor, ou seja, eliminar desperdícios para gerar fluxo.

Os desperdícios destacados nesta filosofia são:

(i) superprodução: produzir muito ou antecipadamente;

(ii) transporte: todo transporte acima do necessário é considerado desperdício; 
(iii) estoques: qualquer estoque acima do mínimo para se executar o trabalho;

(iv) esperas: espera por peças, pelo fim do ciclo são exemplos;

(v) processamento: qualquer processo extra;

(vi) reparos: qualquer conserto;

(vii) movimentação: qualquer movimento que não agregue valor;

(viii) intelectual: qualquer atividade ou falha que consuma o tempo ou talento de uma pessoa, sem agregar valor.

Segundo Womack e Jones [12] o lean tem como pensamento mudanças rápidas no processo, simplificando e reduzindo o ciclo de tempo e geração de defeitos. Cinco etapas são adotadas: 1) Especificar o valor, 2) Identificação da cadeia de valor, 3) Fluxo de valor, 4) Início da implementação, 5) Busca da perfeição.

Seis sigma pode ser definido como:

[...] uma metodologia que busca atingir o sucesso empresarial através de um sistema integrado de gestão com base nas diretrizes da empresa, priorizando ao mesmo tempo os aspectos estratégicos, estruturais, comportamentais e operacionais, monitorados pelas análises estatísticas, para medição e controle em ocorrências disciplinadas e sequências que toda empresa, com o objetivo de otimizar o atendimento das necessidades e expectativas dos clientes, minimizar custos, agregar valores e maximizar os resultados e a competitividade [13].

O método iniciou-se como um conjunto de práticas desenvolvidas pela empresa Motorola para melhorar sistemicamente os processos ao eliminar defeitos.

Conforme Broarin Pinto et al [14], um defeito é uma não conformidade de um produto ou serviço e o seis sigma pode ser definido como uma estratégia gerencial para promover mudanças nas organizações, promovendo melhorias nos processos, produtos e serviços para a satisfação dos clientes. Para Linderman et al [15], o princípio fundamental do seis sigma é o de reduzir de forma contínua a variação nos processos, eliminando defeitos ou falhas nos produtos ou serviços.

O lean seis sigma surgiu a partir da união de duas metodologias, a primeira, o lean manufacturing ou mentalidade enxuta, que surgiu a partir do sistema Toyota de produção por volta de 1980. Com uma filosofia de gestão voltada para redução de desperdícios, fazendo o uso de ferramentas como: kaisen, kanban e poka-yoke, buscava-se a melhoria da qualidade, tempo e custo da produção. A segunda, o seis sigma, que também surge por volta de 1980, a partir de práticas originalmente desenvolvidas pela Motorola, com o foco na redução de defeitos na manufatura, o que impactaria positivamente nos custos. Também é ressaltada a utilização de ferramentas clássicas da qualidade e métodos quantitativos e estatísticos para definição e análise de um determinado problema. É fortemente vinculado o retorno financeiro para organização [16].

O lean seis sigma promove um alinhamento da área de qualidade com as estratégias de negócio da organização, tal desdobramento é realizado por meio de uma estrutura hierárquica que alinha as estratégias e os objetivos de negócio com o portfólio de programa e projetos, os quais estão na base da pirâmide, conforme ilustra a figura 2: 


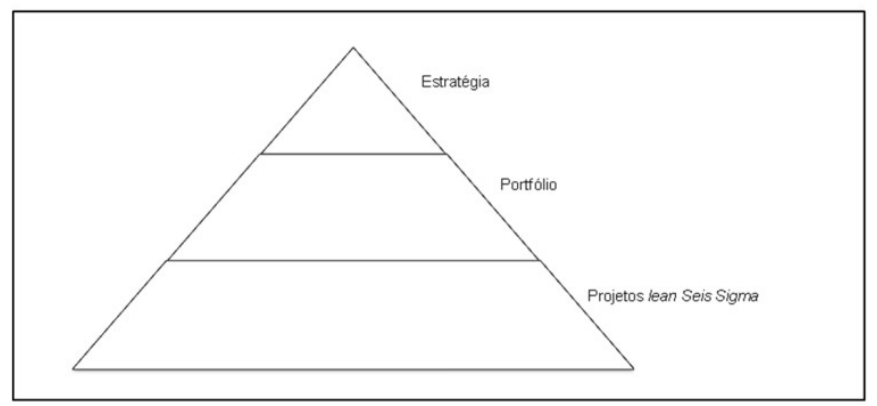

Figura 2: Alinhamento estratégico de projetos. Fonte: adaptado de Carvalho [16]

Por volta de 1990, Jack Welch lidera a implementação da metodologia lean seis sigma na General Eletric (GE) e quebra um paradigma, não atuando somente nas áreas produtivas, mas em todas as áreas de negócios da organização. A evolução é percebida a partir dos anos 2000, com a aderência a metodologia por parte de grandes organizações em diversos segmentos: hospitais (Hospital das Clínicas/SP), empresas de telecomunicações (Telefônica, Telemar), instituições governamentais (INPE, Forças Armadas Norte-Americanas), bancos (Bank of Boston, Bank of America, Citigroup), entre outras.

Os conceitos e aplicações das metodologias são exemplificados na tabela 2 a seguir:

TABELA II

Conceitos e aplicações do lean seis sigma

\begin{tabular}{|c|c|c|}
\hline & Lean & Seis sigmas \\
\hline Escopo & Simples/Curto prazo & $\begin{array}{l}\text { Análises profundas com ferramentas } \\
\text { avançadas / Médio-Longo prazo }\end{array}$ \\
\hline Objetivo & Eliminar desperdícios & $\begin{array}{l}\text { Melhoria de processos com impacto } \\
\text { financeiro }\end{array}$ \\
\hline Etapas & $\begin{array}{ll}\text { 1. } & \text { Especificar Valor } \\
\text { 2. } & \text { Mapear a cadeia de valor } \\
\text { 3. } & \text { Estabelecer fluxo } \\
\text { 4. } & \text { Início da implementação } \\
\text { 5. } & \text { Trabalhar para a perfeição }\end{array}$ & $\begin{array}{ll}\text { 1. } & \text { Definir } \\
\text { 2. } & \text { Medir } \\
\text { 3. } & \text { Analisar } \\
\text { 4. } & \text { Implementar } \\
\text { 5. } & \text { Controlar }\end{array}$ \\
\hline
\end{tabular}

Fonte: desenvolvimento próprio

O lean seis sigma adota o uso de análises estatísticas ( $\sigma$ - sigma - desvio-padrão) e estuda o comportamento do processo sob a ótica dos requisitos críticos para o cliente (CTQ) e da realização do processo (CTP).

De acordo com Rodrigues [13] na década de 1980 o mundo produtivo ainda admitia larga margem para tolerância seus serviços e produtos. Desta forma, no setor industrial, por exemplo, trabalhar com 3 sigma, ou seja, ter uma probabilidade de 66.810 falhas por milhão de itens produzidos e 2 sigma no setor de serviços, probabilidade de 308.770 falhas por milhão de itens, eram margens aceitáveis pelo mercado. Com a maior concorrência, principalmente motivada pela inovação dos produtos japoneses no ocidente a partir de 1980, muitas empresas passaram a perseguir uma maior precisão em seus processos, com menor perda e menos trabalho. A meta passou a ser seis sigma.

A probabilidade de defeitos nesse processo é de 3,4 falhas por milhão de oportunidades, uma probabilidade de 99,99966\% de perfeição. De forma resumida a tabela 3 apresenta um resumo quanto aos níveis sigma, quantidade de falhas por milhão e perfeição esperada:

\section{TABELA III}


Níveis sigma de um processo

\begin{tabular}{|c|c|c|}
\hline Tolerância & Falha por Milhäo de Itens Produzidos & Perfeiçäo Esperada \\
\hline $1 \sigma$ & 691.462 & $30,23 \%$ \\
\hline $2 \sigma$ & 308.770 & $6912 \%$ \\
\hline $3 \sigma$ & 66.810 & $93,32 \%$ \\
\hline $4 \sigma$ & 6.210 & $99,38 \%$ \\
\hline $5 \sigma$ & 233 & $99,9767 \%$ \\
\hline $6 \sigma$ & 3,4 & $99,9996 \%$ \\
\hline
\end{tabular}

Fonte: adaptado de Rodrigues [13]

O lean seis sigma utiliza como direcionador o ciclo DMAIC, que compreende as cinco etapas descritas a seguir:

(iii) análise (A): fase que se busca as fontes de variação ( $\left.\mathrm{X}^{\prime} \mathrm{s}\right)$ que aumentam a variabilidade do processo e que são responsáveis pela geração de defeitos. As principais ferramentas utilizadas são: estatística básica, análise gráfica dos dados, teste de hipótese e análise de regressão;

(iv) melhoria (I): nesta fase toma-se a ação sobre o processo para melhorá-lo com base nas fontes de variação (X's) identificadas na fase de Análise (A). No final desta fase deve-se calcular a nova capabilidade sigma do processo para comprovar que houve uma melhoria significativa. As principais ferramentas utilizadas são: planos de ação, delineamento de experimentos e análise de regressão;

(v) controle (C): é a última etapa. Neste ponto deve-se empregar métodos para monitorar as fontes de variação (X's) identificadas para manter a nova capabilidade adquirida. Deve-se passar a responsabilidade pelo monitoramento do processo para os donos do processo. Uma confirmação dos benefícios econômicos alcançados deve ser feita. As principais ferramentas utilizadas são: cartas de controle, dispositivos à prova de erros e planos de controle.

\section{ESTUDO DE CASO}

O estudo em questão aborda o processo de implementação da metodologia lean seis sigma em uma empresa que foi denominada como Telecomunicações S.A. Uma organização de capital aberto, que atua no segmento de telecomunicações e possui cerca de 13.330 funcionários. Em 2015, obteve um faturamento total de aproximadamente 12,5 bilhões de reais. 
Dentre seus principais serviços oferecidos estão: telefonia local, longa distância nacional e internacional, transmissão de dados, vídeos, internet e soluções via satélite.

O projeto gerou um retorno positivo para a organização com a melhoria de processos relacionados ao atendimento de um determinado produto da empresa cliente, que era voltado para pequenas e médias empresas. Por meio deste projeto, que foi denominado como "redução de ocorrências geradas após a desativação", o gerente do projeto obteve a certificação green belt, concedida aos colaboradores que evidenciam a implementação de um projeto com um retorno para a organização. O mesmo teve a duração total de seis meses, com início em agosto de 2013 e término em fevereiro de 2014, proporcionando a redução de mais de $60 \%$ das faturas emitidas indevidamente após o cancelamento do produto, gerando um custo evitado de aproximadamente R \$ 800.000,00 anualizados.

Na primeira etapa, Definição (D), algumas ferramentas foram exploradas e uma reunião com a equipe do projeto foi realizada no call center localizado em Goiânia/GO que prestava atendimento ao referido produto. A equipe foi formada a partir de pessoas chaves para o desenvolvimento do projeto, que tinham atuação direta no processo em questão.

As ferramentas utilizadas na $1^{\mathrm{a}}$ etapa do projeto lean seis sigma foram:

carta do projeto: definiu-se o problema para atuação; o escopo, que compreende a atuação do projeto e seus limites; o impacto no negócio, apresentando sua relevância a equipe, que deveria compreender quais seriam as pessoas chaves para realização das etapas e o objetivo; que neste projeto visava reduzir em $15 \%$ o volume de emissões de faturas indevidas por erro do atendimento realizado no call center;

(ii) diagrama de Pareto: o produto em questão oferecia três tipos de tecnologias e era disponibilizado em quatro regionais. A partir da análise conclui-se que a maior concentração dos problemas com a emissão de faturas após a desativação estava na tecnologia "Net" com $65 \%$ das ocorrências, todas compreendidas na regional "SP", compreendendo 80-20, conforme gráfico 1.

Gráfico 1: Diagrama de Pareto por tipo de acesso

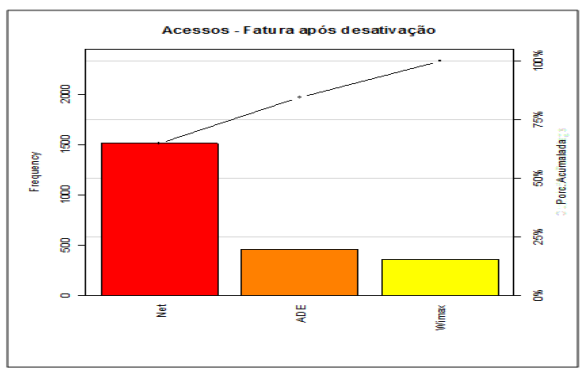

Fonte: desenvolvimento próprio 
(iii) análise histórica (gráfico 2): foi realizado um levantamento a partir de uma aplicação utilizada no atendimento e identificado o histórico de reclamações relacionadas a faturas geradas após desativação dos últimos três meses (julho, agosto e setembro de 2013). A partir de uma análise de correlação entre as faturas geradas após a desativação e os pedidos de cancelamento houve uma tendência positiva em $98 \%$, ou seja, apresentava uma forte relação.

Gráfico 2: Análise histórica

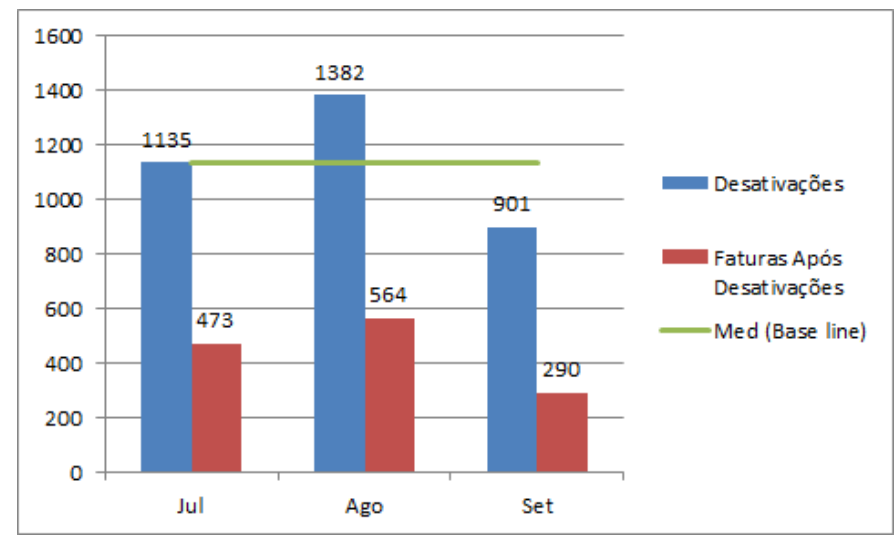

Fonte: desenvolvimento próprio

(iv) a ferramenta utilizada para demonstrar as entradas e saídas do processo, seus fornecedores e clientes foi a SIPOC que é a abreviação para S -suppliers, fornecedores; I -inputs, entradas; P -process, processos; O -outputs, saídas; que no caso em estudo tinha sua causa raiz na desativação e não informava ao sistema de faturamento que o cliente havia solicitado o cancelamento de um determinado serviço. Mapeou-se o macroprocesso de desativação do produto a partir do contato do cliente com o call center (figura 3) e de faturas após a desativação e contato para contestação da cobrança indevida (figura 4):

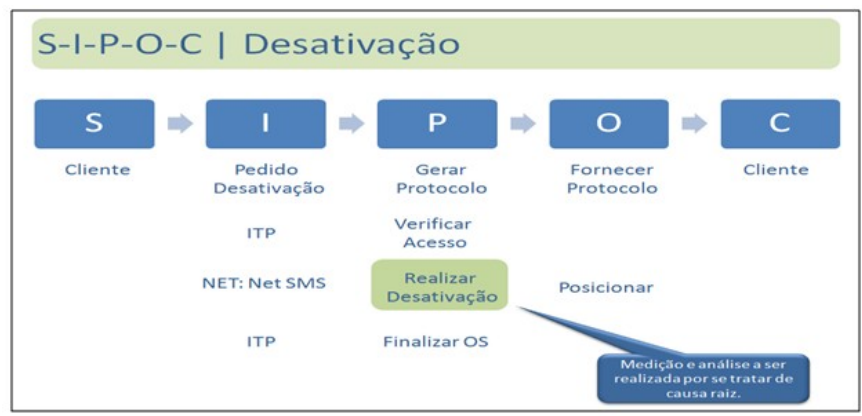

Figura 3: SIPOC - Desativação. Fonte: desenvolvimento próprio 


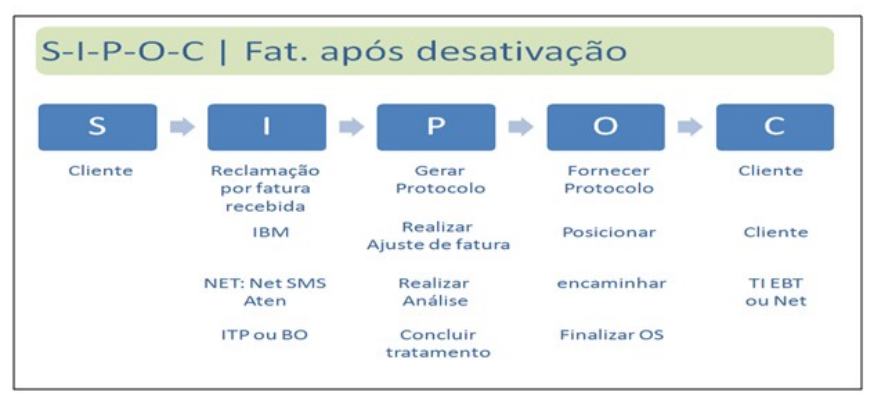

Figura 4: SIPOC - Fatura após desativação. Fonte: desenvolvimento próprio

Na segunda etapa, Medição (M), pôde-se por meio do mapeamento dos processos de atendimento nos cenários de desativação (apêndices a - d) e tratamento das reclamações após a geração de faturas indevidas (apêndice f), além de identificar os X's (possíveis causas), gargalos e impactos. Neste contexto utiliza-se um diagrama de Ishikawa, que busca estabelecer a relação entre o efeito e as causas de um processo, conforme a figura5.

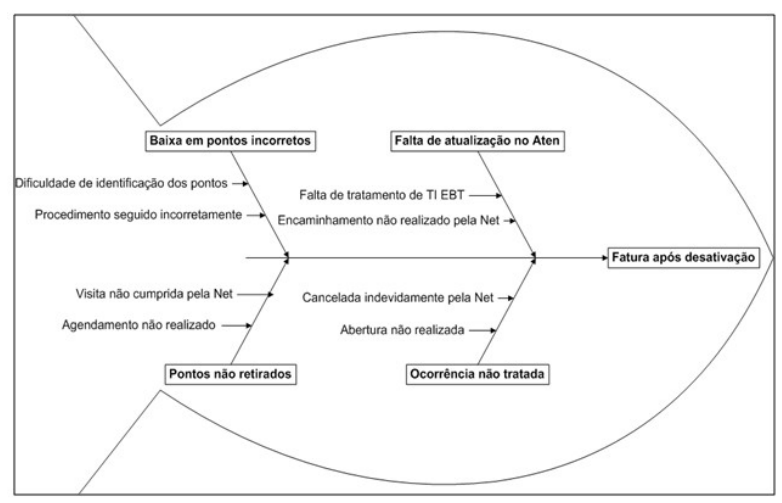

Figura 5: Diagrama de causa e efeito. Fonte: desenvolvimento próprio

$\mathrm{Na}$ terceira etapa, Análise (A), foi criado um FMEA (failure modeand effect analysis), que consiste em uma ferramenta utilizada para análise de falhas potenciais, que são descritas como X's vitais, considerando os seguintes critérios: falhas, causas e efeitos. A partir dessa análise, foi possível definir propostas de ações de melhoria com a intenção de minimizar os impactos. O grupo de pesquisa que atuou no projeto detêm todos os detalhes do FMEA.

A quarta etapa, Implementação (I), descreveu o plano de ação (5W2H) que abordou ações específicas para cada um dos X's considerados vitais para solução do problema.

Para garantir a aplicabilidade das ações definidas na etapa anterior, foi desenvolvido na quinta etapa, uma carta de controle que previa as ações cujo propósito seria de garantir a realização das atividades propostas e o acompanhamento das mesmas:

inclusão de motivos de erro na abertura das ocorrências para tratamento de faturas após desativação, permitindo assim o acompanhamento dos X's (causas vitais) que ainda apresentavam impacto, para prover ações corretivas;

(ii) criação de relatório com os motivos de erros registrados nas ocorrências, para gerar insumos em atuações de reforços de procedimentos e feedbacks pontuais. 
(iii) realização de monitorias focadas no processo de desativação realizado pelos representantes no atendimento do call center, visando prover ações corretivas em eventuais desvios.

Após a implementação do projeto (novembro/2013), foi realizado um acompanhamento dos indicadores durante o período de três meses (gráfico 3), evidenciou-se uma evolução significativa em relação aos erros gerados no início da medição do processo.

Gráfico 3: Redução apresentada pelo projeto lean seis sigma

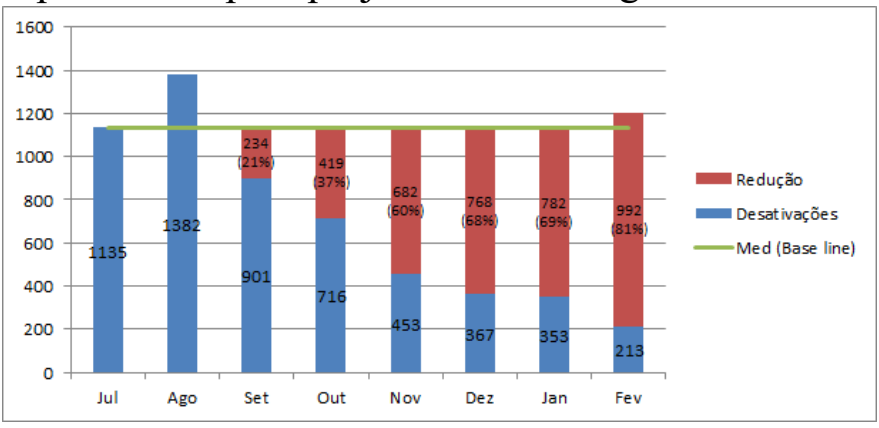

Fonte: desenvolvimento próprio

Em interação com a área financeira, pode-se avaliar o custo evitado anualizado considerando a redução no volume de faturas geradas indevidamente (quadro 4). As perdas geradas estavam relacionadas ao pagamento de impostos com a emissão das faturas indevidas e os custos de emissão das correspondências aos clientes. Considerando o valor médio das faturas geradas na regional SP, extraiu-se o valor cobrado com impostos e emissões e chegou-se a um custo evitado de $\mathrm{R} \$ 815.644,14$ com impostos e $\mathrm{R} \$ 13.426,58$ com emissão de faturas.

Tabela IV

Custo evitado anualizado

\begin{tabular}{|c|c|c|c|c|c|c|c|}
\hline Mês Base (jul) & set & out & nov & dez & jan & fev & $\begin{array}{l}\text { Média (nov, } \\
\text { dez, jan) }\end{array}$ \\
\hline 1135 & 901 & 716 & 453 & 367 & 353 & 213 & 391 \\
\hline Redução & 234 & 419 & 682 & 768 & 782 & 922 & 744 \\
\hline Redução \% & $-21 \%$ & $-37 \%$ & $-60 \%$ & $-68 \%$ & $-69 \%$ & $-81 \%$ & $-69 \%$ \\
\hline ARPU SP & $\mathrm{R} \$ 327,00$ & $\mathrm{R} \$ \mathrm{~S} 12,00$ & $\mathrm{R} \$ \mathrm{~S} 13,00$ & $\mathrm{R} \$ \mathbf{S} 16,00$ & $R \$ 276,00$ & $R \$ 288,00$ & $\mathrm{R} \$ \mathbf{2}_{298,25}$ \\
\hline $\begin{array}{l}\text { Impostos + } \\
\text { Encargos }\end{array}$ & $\mathrm{R} \$ \mathrm{~g}^{24,83}$ & $\mathrm{R} S 9_{90,48}$ & $\mathrm{R} S 9_{90,77}$ & $\mathrm{R} S 9^{91,64}$ & $\mathrm{R} \$ \mathrm{~s}^{2}, 04$ & RS 83,52 & RS 86,49 \\
\hline Emissão & $\mathrm{R} \$ 1,42$ & $\mathrm{R} \$ 1_{1,42}$ & $\mathrm{R} \$ 1,42$ & $\mathrm{R} \$ 1_{1,42}$ & $\mathrm{R} \$ 1,42$ & $\mathrm{R} \$ 1_{1,42}$ & 1,42 \\
\hline \begin{tabular}{|l|}
$\begin{array}{l}\text { Valor da fatura } \\
\text { (média) }\end{array}$ \\
\end{tabular} & $\mathrm{R} \$ 4^{2} 21,83$ & $\mathrm{R} \$^{02,48}$ & $\mathrm{R} \$ 4_{403,77}$ & $\mathrm{R} \$ 4^{2} 07,64$ & $\mathrm{R} \$ \mathrm{~S}^{2} 56,04$ & $R \$ 371,52$ & $\mathrm{R} \$ \mathrm{~S}^{2} 84,74$ \\
\hline $\begin{array}{l}\text { Custo evitado } \\
\text { mês (impostos) }\end{array}$ & $\mathrm{R} \$ \mathbf{2}_{22.190,22}$ & $\mathrm{R} \$ \mathbf{3 7 . 9 1 1 , 1 2}$ & $\mathrm{R} \$ \mathrm{w}^{2} .905,14$ & RS\$ 70.379,52 & $\mathrm{R} \$ \mathrm{~T}^{2} .591,28$ & $\mathrm{R} \$ 77.005,44$ & $\mathrm{R} \$ \mathbf{6 7 . 9 7 0 , 3 5}$ \\
\hline $\begin{array}{l}\text { Custo evitado } \\
\text { mês (emissão) }\end{array}$ & $\mathrm{R} \$ \$ 332,05$ & $\mathrm{R} \$ \$ 594,56$ & $\mathrm{R} \$ \$ 967,76$ & $\mathrm{R} \$ \mathrm{1}_{1.089,79}$ & $\mathrm{R} \$ \mathrm{~N}_{1.109,66}$ & $\mathrm{R} \$ \$ 1.308,32$ & $\mathrm{R} \$ \mathrm{~N}_{1.118,88}$ \\
\hline \begin{tabular}{|l|} 
Projeção 12 \\
meses (impostos) \\
\end{tabular} & RȘ $266.282,64$ & $\mathrm{R} S \$ 454.933,44$ & RȘ 742.861,68 & $\mathrm{R} S \$$ 844.554,24 & RS\$ 751.095,36 & $\mathrm{R} \$ \$ 924.065,28$ & $\mathrm{R} \$ \mathbf{8 1 5} .644,14$ \\
\hline \begin{tabular}{|l} 
Projeção 12 \\
meses (emissão)
\end{tabular} & $\mathrm{R} \$ 3.984,55$ & $\mathrm{R} \$ \mathbf{7 . 1 3 4 , 7 3}$ & $\mathrm{R} \$ 11.613,10$ & $R \$ 13.077,50$ & RS $13.315,90$ & $\mathrm{R} \$ 15.699,82$ & RȘ $13.426,58$ \\
\hline
\end{tabular}

Fonte: desenvolvimento próprio

Após a revisão dos processos, a realização das etapas do projeto e o acompanhamento durante três meses em parceria com o dono do processo para garantir a efetividade das ações, foi concluído o projeto com o objetivo alcançado. Houve na empresa uma média de $60 \%$ de redução com a emissão de faturas indevidas geradas após a 
desativação e pôde-se ainda estender o projeto para demais empresas (participantes do processo), num projeto "guarda-chuva", o que permitiu uma redução bem acima da meta estipulada inicialmente.

\section{CONCLUSÃO}

O trabalho em questão apresenta um estudo de caso que permitiu uma melhor contextualização das etapas de implementação do lean seis sigma e resultados proporcionados.

O estudo trata especificamente de um problema gerado no processo de desativação de serviços que além da cobrança de impostos e emissão das faturas geradas para organização, não tinha como reaver esses valores. O projeto realizado para tratamento do problema exposto foi estruturado com base no fluxo DMAIC, e passou pelas suas cinco fases com a identificação a causa raiz, definição de possíveis soluções, implementação das ações mais adequadas e com maior relevância, acompanhamento dos resultados e criação dos métodos de controle que permitiram perceber a evolução do processo com redução de mais de $60 \%$ dos erros inicialmente identificados, gerando ainda um custo evitado anualizado de mais de $\mathrm{R} \$ 800$ mil reais, durante o período de implementação (entre os anos de novembro de 2013 e fevereiro de 2014).

Pôde-se perceber que a implementação de um projeto lean seis sigma contribuiu para melhoria do processo apresentado, gerando um retorno financeiro com o custo evitado. Porém, tal estudo possui limitações como: segmento específico de atuação e procedimento determinado, ou seja, não se pode definir que o retorno em outras circunstâncias será o mesmo. Conclui-se ainda que projetos lean seis sigma tendem a contribuir para melhoria dos processos avaliados devido a sua metodologia que está baseada em análises estatísticas e ferramentas da gestão da qualidade, podendo gerar um retorno financeiro, no entanto, avaliase que podem não alcançar o objetivo inicialmente proposto em virtude de variáveis como: pessoas, recursos, estruturas organizacionais, tempo disponível, cenário do mercado, entre outras possíveis barreiras. Espera-se que o presente estudo possa ser utilizado a fim de proporcionar uma visão mais clara sobre a metodologia para empresários que desejam implementar ações de melhoria de processos em suas empresas, assim como gerar embasamento aos profissionais que atuam com projetos lean seis sigma.

\section{REFERÊNCIAS BIBLIOGRÁFICAS}

[1] BERNARDES, J.P.F.; MIYAKE, M.Y. Roteiro para Manutenção e Projeto de Integração EDI entre Fornecedores e Clientes no Brasil. Revista IEEE Latin America Transactions, vol.14, n.5, pag. 2470-2478, maio 2016.

[2] VERGARA, Sylvia Constant. Projetos e Relatórios de Pesquisa em Administração. 6 ed. São Paulo, Atlas, 2008.

[3] JURAN, J.M. Juran na liderança pela qualidade; tradução João Mario Csillag. São Paulo, Livraria Pioneira Editora, 1990.

[4] ASSOCIAÇÃO BRASILEIRA DE NORMAS TÉCNICAS. Sistemas de gestão da qualidade - fundamentos e vocabulário: NBR ISO 9000. Rio de Janeiro, 2000.

[5] DEMING, W. E. Qualidade: A Revolução da Administração. Marques. Rio de Janeiro: Saraiva, 1990 
[6] BACK, L., KOVALESKI, L., ANDRADE JUNIOR, P.P. A vigilância tecnológica como ferramenta de gestão de informações: uma revisão da literatura. Revista IEEE Latin America Transactions, vol.13, n.10, pag. 3505-3510, outubro 2015.

[7] FONTANILLAS, C.N.; CRUZ, E.P.; GONÇALVEZ, J.P.S. A gestão do conhecimento e os processos de informações nas organizações: estudo de caso em uma empresa off shore. Sustainable Business International Journal, n. 18, p. 1-28, 2012.

[8] MARANHÃO, M.; MACIEIRA, M.E.B. O Processo nosso de cada dia: modelagem de processos de trabalho. Rio de Janeiro: Qualitymark, 2004.

[9] PORTER, M.E. Vantagem competitiva: criando e sustentando um desempenho superior. Rio de Janeiro: Campus, 1989.

[10] VIEIRA, A.L.B.; VENTURA, M.A.A. Manufatura Enxuta - Aplicação de conceitos na melhoria do processo logístico. Sustainable Business International Journal, n.21, p. 1-23, 2012.

[11] MOREIRA, Otacílio José. Um estudo sobre o impacto da qualidade e produtividade no desempenho da manufatura. Sustainable Business International Journal, n.28, p. 1-13, 2013.

[12] WOMACK, J.P.; JONES, D.T. A Mentalidade Enxuta nas Empresas. 4 ed. Rio de Janeiro, Editora Campus Ltda, 1998.

[13] RODRIGUES, Marcus Vinícius Carvalho. Ações para a qualidade: GEIQ, gestão integrada para a qualidade: padrão seis sigma, classe mundial. Rio de Janeiro: Qualitymark, 2004.

[14] BOARIN PINTO, Silvia Helena; MONTEIRO DE CARVALHO, Marly; LEE HO, Linda. Implementação de programas de qualidade: um Survey em empresas de grande porte no Brasil. Revista Gestão \& Produção. v.13, n.2, p191-203, mai-ago. 2006.

[15] LINDERMAN, K. et al. Six Sigma: a goal-theoretic perspective. Journal of Operations Management, v. 3, n. 21, p. 193-203, 2003.

[16] CARVALHO, M. M. et al. Gestão da Qualidade: teoria e casos. Rio de Janeiro: Elsevier, 2005. 